\title{
Türkiye'de Avrupa Deniz Levreği ve Çipura Yetiştiriciliğinin Üretim ve Ekonomik Göstergelerine Yakından Bir Bakış
}

\author{
Önder YILDIRIM* İsmail Berat ÇANTAŞ \\ Muğla Sitkı Koçman Üniversitesi, Su Ürünleri Fakültesi, Su Ürünleri Yetiştiriciliği, Muğla, Türkiye
}

Atıf yapmak için: Yıldırım, Ö. \& Çantaş, İ.B. (2021). Türkiye'de Avrupa Deniz Levreği ve Çipura Yetiştiriciliğinin Üretim ve Ekonomik Göstergelerine Yakından Bir Bakıș. Anadolu Çev. ve Hay. Dergisi, 6(4), 668-673.

How to cite: Yıldırım, Ö. \& Çantaş, I.B. (2021). A Closer Look at Production and Economic Indicators of European Seabass and Gilthead Seabream Farming in Turkey. J. Anatolian Env. and Anim. Sciences, 6(4), 668-673.

D: https://orcid.org/0000-0003-2591-0310 (DD: https://orcid.org/0000-0002-2074-4985
Öz: Bu çalışmada, Türkiye'de su ürünleri yetiştiriciliğinde son yıllarda en fazla üretilen ilk 3 tür içinde bulunan Avrupa deniz levreği (Dicentrarchus labrax) ve çipura (Sparus aurata) balıklarının genel olarak ve illere göre üretim miktarları, değerleri, işletme sayıları ve kapasiteleri değerlendirilerek ülke ekonomisine katkıları ve potansiyellerinin ortaya konulması amaçlanmıştır. 10 yıllık değişime bakıldığında 2011 yılında ülkemizin yetiştiricilik miktarı 188.790 tondan, 2020 y1lında 421.411 tona çıkmıştır. 2011 yılından 2020 yılına gelindiğinde Avrupa deniz levreği 47.013 tondan 148.907 tona, çipura ise. 32.187 tondan 109.749 tona çıkmıştır. Ülkemizde 2020 yılında yapılan toplam 421.411 ton yetiştiriciliğinin \%61'ini bu iki tür oluşturmaktadır. Avrupa deniz levreğinin ülkemizde 11 ilde, çipura balığının ise 7 farklı ilde yetiştiriciliği yapılmaktadır. Bu iki türün yetiştiriciliğinde de Muğla ilk sırada gelmekte, İzmir ise Muğla'yı takip etmektedir. Balık fiyatları Avrupa deniz levreğinde 2011'de 8,9 TL (5,32 USD) iken, 2020'de 29,53 TL (4,21 USD) olarak görülmektedir. Çipurada ise 2011'de 9,38 TL (5,61 USD) iken, yine 2020 yılında 28,31 TL (4,03 USD) olmuştur. Avrupa deniz levreğinde, ortalama işletme başına üretim miktarı 1.107 ton ile Mersin ilk sırada yer alırken, Çanakkale 33 ton ile en düşük üretime sahiptir. Çipurada ise ortalama tesis başına 1.135 ton ile Aydın ilk sırada yer alırken 11 ton ile Çanakkale son sırada yer almaktadır. Türkiye, dünya deniz balıkları yetiştiriciliği klasmanındaki liderliğini korumak için, zengin su kaynaklarını en optimum noktada kullanmada bilimsel verilerden yola çıkmaktadır. Çevreyle dost ve sürdürülebilir olarak dünya liderliğini koruma isteğini sürdüren ülkemiz Türkiye, gelecek öngörülerini yerli alternatif yem hammaddeleri ar-gelerine hız verme, yeni pazarlara girme, iklim değişikliğinin olası etkilerini en aza indirmek üzerine yoğunlaştırmalıdır.
*Corresponding author:

Önder YILDIRIM

Muğla Sitkı Koçman Üniversitesi, Su Ürünler Fakültesi, Su Ürünleri Yetiştiriciliği, Muğla, Türkiye

$凶:$ onderyildirim@mu.edu.tr

$\underline{\text { Anahtar kelimeler: Türkiye, Avrupa deniz levreği, çipura, iller, ekonomi. }}$

\section{A Closer Look at Production and Economic Indicators of European Seabass and Gilthead Seabream Farming in Turkey}

\begin{abstract}
In this study, the production amounts, values, number of enterprises, and capacities of European sea bass (Dicentrarchus labrax) and gilthead sea bream (Sparus aurata) fish, which are generally among the first 3 species in aquaculture in Turkey (on the basis of provinces), were evaluated. It is also aimed to reveal their contributions to the country's economy and their potential. When the 10-year change is tracked, the aquaculture amount of our country increased from 188790 tons in 2011 to 421411 tons in 2020. From 2011 to 2020, European sea bass increased from 47013 tons to 148907 tons and sea bream. It increased from 32187 tons to 109749 tons. In 2020, these two species account for $61 \%$ of the total 421411 tons of aquaculture in our country. European sea bass is grown in 11 provinces in our country, and sea bream is grown in 7 different provinces. While İzmir follows Muğla, Muğla comes first in the aquaculture of both species. As fish prices were 9.38 TRY (5.61 USD) in European sea bass in 2011, it became 29.53 TRY (4.21 USD) in 2020. While it was 8.9 TRY (5.32 USD) in sea bream in 2011, it became 28.31 TRY (4.03 USD) in 2020. In European sea bass, Mersin ranks first with an average
\end{abstract}




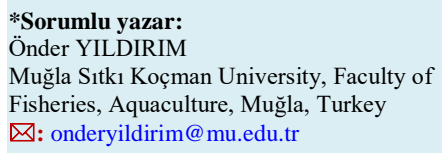

production amount of 1,107 tons per enterprise, meanwhile Çanakkale has the lowest production with 33 tons. In sea bream, Aydın ranks first with an average of 1135 tons per facility, whereas Çanakkale ranks last with 11 tons. To maintain its leadership in the world of marine fish farming, Turkey sets out from scientific outputs in using its rich water resources at the optimum point. Our country, Turkey, which maintains its desire to maintain its world leadership in an environmentally friendly and sustainable manner, should focus its future projections on accelerating R\&D of domestic alternative feed raw materials, entering new markets, and minimizing the possible effects of climate change.

Keywords: Turkey, European sea bass, seabream, provinces, economy.

\section{GİRIŞ}

Dünya su ürünleri üretimi 177,8 milyon tona ulaşmıştır. Bu toplam üretime avcılığın katkısı 92,5 milyon ton olurken, yetiştiricilik üretimi ise 85,3 milyon ton ile neredeyse yarısına ulaşmıştır. Birleşmiş Milletler Gıda ve Tarım Örgütü tarafından su ürünleri yetiştiricilik sektörü, dünyada en hızlı büyüyen gıda üretim sektörü olarak belirtilmektedir (FAO, 2021). Ülkemizde 2020 y1lında, yaklaşık 364.400 ton avcılık, 421.411 ton yetiştiricilik ile toplam 785.811 ton su ürünleri üretimi gerçekleştirilmiştir. Toplam ihracat 2020 yilinda 201.157 ton olarak kaydedilmiştir. Ülkemizde yapılan su ürünleri üretim miktarının, 559.932 tonu iç piyasa tarafindan tüketilirken, 107.223 tonu ise balık unu ve balık yağı yapımında hammadde olarak değerlendirilmiştir. 2020 yılında, yetiştiriciliği yapılan en önemli türler 148.907 ton ile Avrupa deniz levreği, 144.182 ton ile gökkuşağı alabalığı ve 109.749 ton ile çipura olmuştur (TÜİK, 2021).

2020 yılında deniz ve içsularda toplam tesis sayısı 2.139 iken toplam proje kapasitesi ise 516.784 ton olarak görülmektedir. Deniz balıkları tesis sayısı 432 adet olup, toplam proje kapasitesi ise 306.124 ton üretim gerçekleştirilmiştir. Deniz balıkları yetiştiriciliğin, toplam yetiştiricilik üretimindeki payı 293.175 tondur $(\% 69,9)$. Ülkemizde su ürünleri yetiştiriciliğinin toplam değeri 2020 y1lında 10,8 milyar TL (1,54 milyar dolar) olarak görülmektedir (TÜİK, 2021).

$\mathrm{Su}$ ürünleri, insan beslenmesine olan katkısı, istihdam oluşturması, gıda ve su ürünlerine sanayine hammadde sağlaması ve ihracatı yapılan en önemli canlı gıda ürünü olması nedeniyle ülke ekonomimiz için oldukça önemli bir yere sahiptir (Aydın ve Sayılı, 2009; TÜİK, 2021). Özellikle artan dünya nüfusu ile beraber talebi yükselen protein ihtiyacı ve doğal balık stoklarının çeşitli nedenlerle azalması, su ürünleri yetiştiriciliğine yönelik yatırımları arttırmaktadır (Çavdar, 2009). Dünya su ürünleri üretiminin artışının, geçmişe göre daha yavaş olmasına rağmen, arz-talep açığını doldurması beklenmektedir (FAO, 2018).

Dünya'da 2019 y1lında Avrupa deniz levreği 263.215 ton, çipura ise 258.754 ton yetiştirilmiştir. Dünya su ürünleri yetiştiricilik üretimi içinde (FAO, 2021) \%0,3 'lük paya sahip olan Türkiye, denizel yetiştiricilikte Akdeniz havzasında bir numaralı yetiştirici ülke konumunda olduğu görülmektedir (Tolon, 2019). Avrupa Birliğinde toplam Avrupa deniz levreği yetiştiriciliği 82.758 ton iken, çipura yetiştiriciliği 91.091 ton üretim gerçekleşmiştir. Sırasıyla Avrupa deniz levreği ve çipura toplam yetiştiricilik içinde $\% 11$ ve \%7'lik payı oluşturmaktadırlar (FAO, 2021).

Türkiye'nin deniz balıkları yetiştiriciliğinde önemli iki türü çipura ve levrek balıklarının üretim miktarları incelendiğinde her geçen yıl üretimin arttığı görülmektedir. Ülkemizde son 10 yılda olduğu gibi 2020 yılında da Avrupa deniz levreği ve çipura yetiştiriciliği yapılan ilk 3 tür arasına girmektedir. Avrupa deniz levreği ve çipura yetiştiricilik sektöründeki yakalanan ivmenin sürdürülebilir olması ülke ekonomisi açısından oldukça önemlidir.

Ülkemizin su ürünleri açısından başlıca ihracatını AB ülkeleri oluşturmaktadır. Bu bağlamda Avrupa birliğine en fazla ihracatı yapılan ürünlerin Avrupa deniz levreği ve çipura olduğu, Avrupa Birliği ülkeleri arasında en başta gelen rekabet ettiğimiz ülkelerin İspanya, İtalya ve Yunanistan olduğu görülmektedir. 2000 yılında 139 milyon TL olan toplam değerin, 2003 y1lında 415 milyon TL, 2012 yılında 1,6 milyar TL ve 2016 yılında ise 3,2 milyar TL olduğu bilinmekte (Anonim, 2018), 2020 yılında ise bu rakamın 10,8 milyar TL olduğu dikkat çekmektedir. Türkiye su ürünleri yetiştiricilik sektörü, destek ve teşvikleri içeren su ürünleri politikaları ile 2023 yılında 600 bin ton su ürünleri üretimi ve 2 milyar dolar ihracat gelirini hedeflemektedir (TAGEM, 2019).

$\mathrm{Bu}$ çalışmada, Avrupa deniz levreği ve çipura yetiştiriciliğinin, iller bazında yetiştiricilik miktarları, değerleri, işletme sayıları, proje kapasiteleri incelenerek, son on yıllık yakın geçmişten günümüze doğru Türkiye profili ortaya çıkarılmıştır.

\section{MATERYAL VE METOT}

Yapılan bu çalışmadaki Avrupa deniz levreği ve çipuraya ait yetiştiricilik verileri (miktar, fiyat), Türkiye İstatistik Kurumu ve ilgili Tarım ve Orman İ Müdürlüklerinin web sayfalarından süzülerek elde 
edilmiştir. İşletme sayıları ve kapasiteleri ise Tarım ve Orman Bakanlığı, Balıkçılık ve Su Ürünleri Genel Müdürlüğü internet sitesinde yer alan güncel su ürünleri yetiştiricilik tesisleri listesinden derlenmiştir. Elde edilen veriler tablolar haline getirilerek bulgular bölümünde irdelenmiştir. Güncel Avrupa deniz levreği ve çipura fiyatlarının üretim maliyetleri ise firmalarla ikili görüşmeler neticesinde elde edilmiştir.

\section{BULGULAR}

2020 yılında yetiştiricilikte ilk sırada bulunan Avrupa deniz levreği 148.907 ton üretim miktarına ulaşmıştır. Son 10 yılda ülkemizde yapılan levrek yetiştiriciliğin miktarı (Ton), değeri (TL ve USD) ve üretim yapılan il sayısı Tablo 1'de gösterilmektedir.

Muğla deniz balıkları yetiştiriciliğinde 205 Avrupa deniz levreği, 203 çipura işletmesi ile ilk sırada yer almaktadır. Muğla ili sahil şeridinin girintili-çıkıntılı yapısı ve yaklaşık 1124 km'lik kıyı uzunluğuna sahip olması Muğla'yı diğer illere göre daha avantajlı bir konuma getirmiştir. Yine, Ege bölgesinde yer alan İzmir 50 Avrupa Deniz Levreği, 48 Çipura işletmesi ve Aydın ise 16 Avrupa deniz levreği ve 15 Çipura işletmesi işletme ile Muğla ilini takip etmektedirler.

Tablo 1. Türkiye'de son 10 yılda Avrupa deniz levreği yetiştiriciliği (BSGM, 2021; TÜİK, 2021).

Table 1. European seabass aquaculture production in last ten years in Turkey.

\begin{tabular}{lcccc}
\hline $\begin{array}{l}\text { Avrupa Deniz Levreği } \\
\text { (Türkiye Düzeyi) }\end{array}$ & Miktar & $\begin{array}{c}\text { Değer } \\
\text { (TL) }\end{array}$ & $\begin{array}{c}\text { Değer } \\
\text { (USD) }\end{array}$ & $\begin{array}{c}\text { Üretim Yapılan } \\
\text { II Sayısı }\end{array}$ \\
\hline $\mathbf{2 0 1 1}$ & 47.013 & 8,90 & 5,32 & 8 \\
$\mathbf{2 0 1 2}$ & 65.512 & 10,99 & 6,13 & 11 \\
$\mathbf{2 0 1 3}$ & 67.912 & 10,48 & 5,51 & 11 \\
$\mathbf{2 0 1 4}$ & 74.653 & 12,06 & 5,53 & 11 \\
$\mathbf{2 0 1 5}$ & 75.164 & 13,51 & 4,96 & 10 \\
$\mathbf{2 0 1 6}$ & 80.847 & 16,80 & 5,56 & 8 \\
$\mathbf{2 0 1 7}$ & 99.971 & 18,56 & 5,09 & 10 \\
$\mathbf{2 0 1 8}$ & 116.915 & 20,95 & 4,35 & 10 \\
$\mathbf{2 0 1 9}$ & 137.419 & 23,41 & 4,12 & 11 \\
$\mathbf{2 0 2 0}$ & 148.907 & 29,53 & 4,21 & 11 \\
\hline *TCMB, (2012-2021) & & & &
\end{tabular}

İllere göre Avrupa deniz levreği yetiştiriciliğini özetlemek gerekirse 2020 yılında ülkemizde 11 ilde levrek yetiştiriciliği gerçekleştirilmiş Muğla 65.750 ton ile ilk sırada, İzmir 55.156 ton ile ikinci sırada, Aydın ise 18.166 ton ile 3. Sırada yer almaktadır. Avrupa deniz levreği yetiştiriciliği yapılan illerdeki 2020 yılı üretim miktarları Tablo 2'de gösterilmektedir.

Tablo 2. İllere göre Avrupa deniz levreği üretim miktarları (BSGM, 2021; TÜİK, 2021).

Table 2. European seabass aquaculture production by provinces.

\begin{tabular}{|c|c|c|c|c|c|c|}
\hline Avrupa Deniz Levreği Üretimi İllere Göre (2020) & iller & Üretim Miktarı (Ton) & Türkiye içindeki payı (\%) & İşletme Sayısı & Türkiye içindeki payı (\%) & Proje Kapasitesi (Ton)* \\
\hline 1. & Muğla & 65.750 & 44,15 & 205 & 65,07 & 67.068 \\
\hline 2. & İzmir & 55.156 & 37,04 & 50 & 15,87 & 74.400 \\
\hline 3. & Aydin & 18.166 & 12,19 & 16 & 5,07 & 18.220 \\
\hline 4. & Samsun & 4.300 & 2,88 & 10 & 3,17 & 9.874 \\
\hline 5. & Antalya & 1.544 & 1,03 & 5 & 1,58 & 2.150 \\
\hline 6. & Hatay & 1.389 & 0,93 & 3 & 0,95 & 1.650 \\
\hline 7. & Mersin & 1.190 & 0,79 & 10 & 3,17 & 2.545 \\
\hline 8. & Ordu & 622 & 0,41 & 6 & 1,90 & 950 \\
\hline 9. & Trabzon & 621 & 0,40 & 7 & 2,22 & 1.000 \\
\hline 10. & Sinop & 158 & 0,10 & 2 & 0,63 & 987 \\
\hline 11. & Çanakkale & 11 & 0,08 & 1 & 0,31 & 13 \\
\hline TOPLAM & 11 & 148.907 & 100 & 315 & 100 & 178.857 \\
\hline
\end{tabular}

Ülkemizde son yıllarda ve 2020 yılında yetiştiriciliği yapılan türler arasında 3. Sırada çipura gelmekte olup, 2020 yllında 109.749 ton yetiştiricilik gerçekleştiği görülmektedir. Son 10 yllda ülkemizde yapılan çipura yetiştiriciliğin miktarı (ton), değeri (kg başına TL fiyat) ve üretim yapılan il sayısı Tablo 3'te gösterilmektedir.

Tablo 3. Türkiye'de Son 10 yılda çipura yetiştiriciliği (BSGB, 2021; TÜIK, 2021).

Table 3. Gilthead sea bream aquaculture production in last ten years in Turkey.

\begin{tabular}{ccccc}
\hline Çipura (Türkiye Düzeyi) & Miktar & $\begin{array}{c}\text { Değer } \\
\text { (TL) }\end{array}$ & $\begin{array}{c}\text { Değer } \\
\text { (USD)* }\end{array}$ & $\begin{array}{c}\text { Üretim Yapılan } \\
\text { İl Sayısı }\end{array}$ \\
\hline $\mathbf{2 0 1 1}$ & 32.187 & 9,38 & 5,61 & 5 \\
$\mathbf{2 0 1 2}$ & 30.743 & 8,97 & 5,01 & 7 \\
$\mathbf{2 0 1 3}$ & 35.701 & 9,62 & 5,05 & 8 \\
$\mathbf{2 0 1 4}$ & 41.873 & 11,04 & 5,06 & 8 \\
$\mathbf{2 0 1 5}$ & 51.844 & 12,83 & 4,71 & 7 \\
$\mathbf{2 0 1 6}$ & 58.254 & 14,04 & 4,64 & 7 \\
$\mathbf{2 0 1 7}$ & 61.090 & 16,66 & 4,57 & 8 \\
$\mathbf{2 0 1 8}$ & 76.680 & 19,70 & 4,09 & 8 \\
$\mathbf{2 0 1 9}$ & 99.730 & 21,89 & 3,86 & 7 \\
$\mathbf{2 0 2 0}$ & 109.749 & 28,31 & 4,03 & 7 \\
\hline *TCMB, (2012-2021) & & & &
\end{tabular}

Ülkemizde çipura yetiştiriciliğine bakacak olduğumuzda, 2020 yılında ülkemizde 7 ilde gerçekleştirilmiş olup, çipura yetiştiriciliğinde Muğla 52.000 ton ile ilk sırada, İzmir 33.389 ton ile ikinci sırada, Mersin ise 17.719 ton ile 3. Surada yer almaktadır. Çipura yetiştiriciliği yapılan illerin 2020 yılı üretim özeti Tablo 4 'te gösterilmiştir.

Ülkemizde, toplam Avrupa deniz levreği işletmesi 315 adet, çipura yetiştiricilik tesisi ise 290 adettir. En yüksek Avrupa deniz levreği üretimine sahip olan Muğla ilinin işletme sayısı bakımından çiftlik başına ortalama 320 ton üretim yaptığı görülmüştür. Muğla ilinin üretim bakımından 1. olmasına rağmen tesis başına üretim ortalamasının düşük olmasının sebebi, Milas ilçesinde yer alan toprak havuzlarda üretim yapan kapasitesi 50 ton altındaki işletmelerin çok sayıda olmasıdır. Aydın ili 1.135 ton ile tesis başına ortalama en yüksek üretimi yakalamıştır. Avrupa deniz levreğinde en düşük üretim 1 
tesisi bulanan Çanakkale'de gerçekleşmiş olup tesis başına üretim 11 ton olarak görülmektedir. Çipura açısından bakacak olursak en fazla tesis 203 adetle Muğla'da görülürken, tesis başına ortalama 256 ton üretim gerçekleştirilmiştir. Tesis başına ortalama üretimde 1.107 ton ile Mersin ilk sırada gelmektedir. En düşük üretim ise 1 tesisi bulunan Çanakkale'de ortalama 33 ton olarak gerçekleştirilmiştir.

Tablo 4. İllere göre çipura üretimi (BSGM, 2021; TÜİK, 2021).

Table 4. Gilthead sea bream production by province.

\begin{tabular}{|c|c|c|c|c|c|c|}
\hline Çipura Üretimi İllere Göre (2020) & iller & Üretim Miktarı (Ton) & Türkiye İçindeki Payı (\%) & İşletme Sayısı & Türkiye İçindeki Payı (\%) & Proje Kapasitesi(Ton)* \\
\hline 1. & Muğla & 52.000 & 47,38 & 203 & 70 & 56.148 \\
\hline 2. & İzmir & 33.389 & 30,42 & 48 & 16,55 & 71.900 \\
\hline 3. & Mersin & 17.719 & 16,14 & 16 & 5,51 & 14.685 \\
\hline 4. & Antalya & 4.128 & 3,76 & 5 & 1,72 & 3.730 \\
\hline 5. & Hatay & 1.843 & 1,67 & 2 & 0,68 & 2.600 \\
\hline 6. & Aydın & 637 & 0,58 & 15 & 5,17 & 734 \\
\hline 7. & Çanakkale & 33 & 0,03 & 1 & 0,34 & 25 \\
\hline Toplam & 7 & 109.749 & 100 & 290 & 100 & 149.822 \\
\hline
\end{tabular}

*BSGM, (2021)

\section{TARTISMA}

Deniz balıkları yetiştiriciliğinde 1980'li yıllardan başlayan faaliyetler, istatistiki olarak 1986 yılındaki verilere bakıldığında, sadece 35 ton olarak yansımış ve 1996 yılında 15.241 tona yükselmiştir. 2020 yılına gelindiğinde yaklaşık 293 bin tona ulaşarak, tüm zamanların rekorunu da kırmıştır.

Avrupa deniz levreği ve çipura yetiştiriciliğin ülkemizde bu denli yüksek olmasının sebeplerinden biri, denizlerde yüksek kapasiteli üretimin yapılabilme imkânından kaynaklanmaktadır. Yetiştiricilik tesislerinin çoğu 0-50 ton/yıl kapasite grubundaki küçük işletmelerden meydana gelmekte ve denizlerde 1000 ton/yıl üzerinde 80 işletme bulunurken, iç sularda bu sayının 3 olduğu görülmektedir (TAGEM, 2019). Ülkemizde 2020 y1lında üretim yapan 315 Avrupa deniz levreği ve 290 adet çipura işletmesi olduğu görülmektedir. Bu işletmelerin üretiminin büyük kısmı ağ kafeslerde gerçekleşirken, toprak havuz işletmeleri de bulunmaktadır. Ağ kafes işletmelerin büyük bir çoğunluğu Ege Bölgesinde faaliyet göstermektedir.

Baki ve Dalgıç (2009), yaptıkları çalışmada Ordu ilinde işletmelerin ikinci bir tür olarak yetiştiriciliğe başladığını Avrupa deniz levreği üretim kapasitelerinin (60-120 ton/yıl), Ege Bölgesi’ndeki ağ kafes (500-1000 tonluk) işletmelerine oranla daha düşük olduğu belirlenmiştir. İşletmeler kapasitelerini artırma çabası içinde olsalar bile, hâkim rüzgâr ve yüksek dalgalardan daha az etkilenen kısmen korunaklı alanların genişleme imkânı olmayacak derecede sınırlı olması nedeniyle bunu gerçekleştiremedikleri tespit edilmiştir. Çevresel şartlar ve türün istediği su kalitesi özelliklerinden dolayı Avrupa deniz levreği yetiştiriciliği Ege bölgesinde daha baskın olarak yapılmaktadır.

Taş (2007) yaptığ Koyu'nda 2006 yılında 634 ton levrek üretim gerçekleştiğini tespit etmiş, bizim çalışmamızda verilen rakamlara göre Ordu ili levrek yetiştiriciliği 2020 yılında, 622 ton olarak görülmektedir. $\mathrm{Bu}$ durumda levrek yetiştiriciliğin bu bölgede Ege bölgesi gibi artmadığı ama belirli bir istikrarı koruduğu görülmektedir.

Karadeniz Bölgesi'nde yoğun yetiştiricilik yapılmadığı için yaygın hastalıklar bulunmaması ve düşük tuzluluktan kaynaklanan lezzet fark1 gibi nedenlerle pazarda tercih edilmesinin bölgede avantaj sağladığ belirtilmektedir (SÜMAE, 2012).

Hekimoğlu ve Altındeğer (2012) yaptıkları çalışmada Samsun ilinin 2010 yılında su ürünleri üretimine katkısını toplam 23.483 ton olduğunu tespit etmişlerdir. Yaptığımız bu çalışmada, Samsun ilinin 2020 yılı Avrupa deniz levreği yetiştiriciliği miktarı 4.300 ton ile Türkiye'de 4. ve önemli bir konumdadır.

Türkiye'de 2003 yılı verilerine göre 1215 adet alabalık, 86 adet sazan ve 358 adette çipura, levrek ve orkinos işletmesi olmak üzere toplam 1659 adet işletme vardır (Tekelioğlu, 2007). 2020 yılına gelindiğinde ise toplam işletme sayısının 2.139 olduğu ve üretimdeki teknolojik gelişmeler ayrıca bilgi donanımı ile birlikte üretimin arttı̆̆ dikkat çekmektedir.

Yıldırım ve Okumuş (2004) yılında yaptıkları çalışmada Muğla ilinin 21.795 ton üretimiyle, Türkiye su ürünleri yetiştiriciliğinin yaklaşık \%36'sını karşıladığını, Muğla'nın Türkiye üretimindeki payı çipurada yaklaşık $\% 75$, levrekte \%64 olduğunu tespit etmişlerdir. Bu çalışmada, Muğla ili 141.959 ton yetiştiricilik ile ülkemizdeki toplam üretimin \%34'ünü, Avrupa deniz levreği üretiminin \%44'ünü, çipura üretiminin ise \%47'sini oluşturduğu görülmüştür. Muğla ilinin üretim payındaki bu azalmanın sebebinin diğer illerde de başlayan ve artış gösteren çipura ve Avrupa deniz levreği yetiştiriciliğinden kaynaklanmaktadır.

Yaptığımız ikili görüşmelere göre Avrupa deniz levreğinin 2021 yılında (Ekim ayı) maliyeti (yem, yavru gideri ve diğer giderler) ortalama 37 TL (4,5 USD) iken balık marketlerinde satış fiyatının ortalama 60-65 TL (7,31-7,92 USD), çipura balığının maliyeti 35 (4,2 USD) iken, balıkçı tezgahlarında satış ortalaması 50-55 TL $(6,09$ 6,70 USD) olarak görülmektedir. Üretim dönemi boyunca 
Avrupa deniz levreğinde yem giderinin yaklaşık $\% 65$, çipurada ise $\% 60$ olduğu elde edilen bilgiye göre saptanmıştır. Korkut ve Yıldırım (2003), yaptıkları çalışmada yem giderlerinin tüm maliyet unsurları içindeki değerleri balıklara göre incelendiğinde çipurada $\% 57$ ve levrekte $\% 59$ olduğunu ve yem giderlerinin yetiştiricilikte önemli bir maliyet oluşturduğu ortaya koymuşlardır. Yem giderlerinin işletme giderleri içinde oransal olarak daha fazla çıkması, özellikle döviz üzerinden ithal hammaddelere bağlanması beklenen bir durumdur. Yetiştiriciliğin gelişmesinde üretim miktarı ve değeri etkileyen unsurların başında da yem giderlerinin geldiği aşikardır.

BAKKA (2021) raporuna göre Zonguldak ilinde 1000 Tonluk bir Avrupa deniz levreği işletmesinin kuruluş maliyetinin 1,1 milyon dolar olduğu görülmektedir. Yine 1000 tonluk çipura üretim tesisinin kuruluş maliyeti 1,03 milyon dolar olduğu tespit edilmiştir. 1000 tonluk standart bir üretimde geri dönüş süresinin 6-8 yıl arasında olacağ 1 tahmin edilmektedir (Çukurova Kalkınma Ajans1, 2020). Su ürünleri sektöründe daha yüksek fiyatların olacağı bir 10 y1llık dönem beklenmektedir. Bu fiyatlara, artan nüfus, avcılıkta yaşanan düşüşler, et fiyatlarındaki artış ve üretim maliyetlerinin artması (yem ve akaryakıt giderleri vb.) neden olacağı düşünülmektedir (BAKKA, 2021). 2030 yılındaki fiyatlandırmanın günümüze göre dolar bazında yaklaşık \%25 oranında artış göstereceği tahmin edilmektedir (FAO, 2018). Balık unu ve balık yağ 1 fiyatlarındaki artış da burada etkili olacaktır.

\section{SONUC}

Ülkemiz, su ürünleri üretiminde 1 milyon tonluk miktarı yakalamasına, az bir zamanın kaldığı rakamlardan anlaşılmaktadır. 2023 yılı hedefindeki yetiștiricilik vasıtasıyla üretim miktarı olan 600 milyon tona ise adım adım yaklaşmaktadır. 2020 yılına ait, 421.411 tonluk yetiştiricilik üretiminin \%35'i Avrupa deniz levreğinden, \%26'sı çipuradan gelmiştir.

Ülkemiz su ürünleri yetiştiriciliği 1984 yllında 2.284 ton iken, 1999 yllinda 63.000 ton 2011 yilında 188.790 ton ve 2020 y1lında da 421.411 tona yükselerek büyük bir değişim göstermiştir. İşletme sayısı ise 1999 yılında 1.079 iken 2020 yılında ise 2.193 adete çıkmıştır.

2020 yllında Türkiye'de toplam 421.411 ton yetiştiricilik yapılmıştır. 11 ilde toplam 148.907 tonu Avrupa deniz levreği yetiştirilmiş olup, ortalama değeri kg başına 29,53 TL (4,21 USD) olarak gerçekleşmiştir. 7 ilde 109.749 ton çipura yetiştiriciliği yapılmış olup, ortalama değeri $\mathrm{kg}$ başına 28,31 TL (4,03 USD) olduğu tespit edilmiştir.

Koronavirüs (Covid-19) salgınının 2020 yılının mart ayında baş göstermesi üzerine, özellikle beslenmeyle bağışıklık sisteminin güçlendirilmesi tavsiye edilmiştir. Özellikle dengeli beslenme ile birlikte vitamin D, çinkodemir minerali ve omega-3 yağ asitleri (DHA-EPA) barındıran balık tüketimi ilk akla gelenler arasında yerini almıştır. Halkımızın pandemi süresince balık tüketimine yönelik birtakım kampanyalar, Tarım ve Orman Bakanlığı, Balıkçılık ve Su Ürünleri Genel Müdürlüğü öncülüğünde gerçekleşmiştir. Çipura ve Avrupa deniz levreği maliyetine yakın fiyatlar ile (22,90 TL; 24,90 TL- 3,30-3,59 USD; Nisan 2020) satı̧̧a çıkarılmıştır.

Ülkemizde su ürünleri yetiştiriciliği iklim ve çevre koşullarının uygun olduğu, 74 ilde gökkuşağı alabalığı, 11 ilde Avrupa deniz levreği yetiştiriciliği ve 7 ilde çipura yetiştiriciliği yapılmaktadır. Diğer türlerde olduğu gibi, deniz balıkları yetiştiriciliğinde özellikle Avrupa deniz levreği ve çipura üretiminde bilimsel verilerden faydalanarak hareket edilmektedir. İşletmelerin en önemli giderlerini yem oluştururken Avrupa deniz levreği ve çipura yetiştiriciliğinde yem değerlendirme oranları (FCR) 1,5-2,0 arasında değişmekte ortalama 1,8 düzeyinde görülmektedir. Toplam üretim rakamlarına bakıldığında, yetiştirilen Avrupa deniz levreği için 266.400 ton, çipura için ise 196.200 ton yem kullanılmış olduğu tahmin edilmektedir. Balık yem rasyonlarının (farklı balık büyüklük safhaları için kullanılan yavru ve büyütme yemleri içinde) $\% 20-40$ 'ını balık unu ve \%10-20 arasında da balık yağı kullanımı oluşturmaktadır. Bu iki esas hammaddenin ülkemiz çerçevesinde üretimi yetecek düzeyde olmadığı için, çok büyük bir kısmı ithal edilmekte ve ciddi bir maliyet oluşturmaktadır. Buna ilaveten gün geçtikçe de artan hammadde maliyetlerinden dolayı, yem fiyatları da yükselmektedir. Bu nedenle alternatif yerli yem hammaddelerin bugünden başlanarak ar-ge çalışmalarına hız verilmesi gelecekte bu noktadaki açığımızı azaltabilecektir. Yem hammadde seçiminde çevreyle dost ilişkinin kurulması ayrı bir öneme sahiptir. Su ürünleri yetiştiriciliğinin sürdürülebilirliği sağlanırken, aynı zamanda çevresel etkilerin de en aza indirilmesi de amaçlanmalıdır. İklim değişikliğinin olası etkilerinin en önce görüldüğ̈̈ yer olan sucul ortam için yetiştiricilik faaliyetleri için bölgesel öngörüler şimdiden ele alınmalıdır. Aynı şekilde değisşen ortam için uygun türler üzerinde de durulmalıdır. Mevcut pazarların sağlamlaştırılması ve yeni alternatifler pazarlar için ihracatı geliştirme modellemeleri planlanmalıdır.

\section{KAYNAKLAR}

Aydın, O. \& Sayılı, M. (2009). Samsun İlinde Alabalık Işletmelerinin Yapısal ve Ekonomik Analizi. GOÜ Ziraat Fakültesi Dergisi, 26(2), 97-107.

Baki, B. \& Dalgıç, G. (2009). Ordu İli Perşembe İlçesinde Levrek (Dicentrarchus labrax L., 1758) Yetiştiriciliği Yapan İşletmelerde Üretim ve 
Teknik Özellikler. Anadolu J. Agric. Sci. 24(1), 8-1.

BAKKA. (2021). Zonguldak İli Levrek, Gökkuşağı Alabalığı ve Deniz Alabalığı Yetiştiriciliği, Ön Fizibilite Raporu, T.C. Sanayi ve Teknoloji Bakanlığı. $74 \mathrm{Sf}$.

BSGM. (2021). Balıkçılık ve $\mathrm{Su}$ Ürünleri Genel Müdürlüğü,

https://www.tarimorman.gov.tr/BSGM/Belgeler/ Icerikler/Su\%20\%C3\%9Cr\%C3\%BCnleri\%20Y eti\%C5\%9Ftiricili\%C4\%9Fi/Su-UrunleriTesisleri-2019.pdf (21 Ekim 2021).

Çukurova Kalkınma Ajansı. (2020). Adana Ili Çipura Üretim Tesisi, Ön Fizibilite Raporu, T.C. Sanayi ve Teknoloji Bakanlığı. 34s.

FAO.

(2018).

http://www.fao.org/3/CA0191TR/Ca0191tr.Pdf (21 Ekim 2021).

FAO. (2021). Global Production Statistics 1950-2017. http://www.Fao.Org/Fishery/Statistics/Globalproduction/Query/En. (21 Ekim 2021).

Hekimoğlu, B. \& Altındeğer, M. (2012). Türkiye ve Samsun İlinde Su Ürünleri Sektörünün Mevcut Durumu Sorunları ve Çözüm Önerileri, Samsun Valiliği Gıda Tarım ve Hayvancılık İl Müdürlüğü, $35 \mathrm{~s}$.

Korkut, A.Y. \& Yıldırım, Ö. (2003). Türkiye'de Su Ürünleri Yetiştiriciliği ve Yetiştiricilikte Alternatif Yem Kaynakları E. Ü. Su Ürünleri Dergisi. 20(1-2), 247-255.

SÜMAE. (2012). Doğu Karadeniz Bölgesi Su Ürünleri Sektör Raporu. Su Ürünleri Merkez Araştırma Enstitüsü, Trabzon. 107s.

TAGEM. (2019). Su Ürünleri Sektör Politika Belgesi. https://www.tarimorman.gov.tr/TAGEM/belgeler /yayin/su\%20ürünleri\%20sektör\%20politika\%20 belgesi\%202019- 2023.Pdf. (15.11.2020).

Taş, B. (2007). Vona Koyu'nda (Güney Karadeniz, Ordu, Türkiye) Su Ürünleri Yetiştiriciliği. Journal of Fisheriessciences.Com. 1(4), 176-183. https://doi.org/10.3153/Jfscom.2007021

TCMB. (2021). Türkiye Cumhuriyeti Merkez Bankası Ortalama Döviz Kurlar1, https://www.tcmb.gov.tr/wps/wcm/connect/67c9 $353 \mathrm{c}-\mathrm{d} 201-40 \mathrm{fb}-9 \mathrm{e} 19-$ a99dd1653d6e/Rom+ortalama+kur.Xlsx?Mod=aj peres\&cacheid=rootworkspace-67c9353c-d20140fb-9e19-a99dd1653d6e-mq-iiag (30/10/2021).

Tekelioğlu, N., Kumlu, M., Yanar, M., \& Erçen, Z. (2007). Türkiye'de Su Ürünleri Üretimi Sektörünün Durumu ve Sorunları.

Tolon, T. (2019). Türkiye'de Geçmişten Günümüze Tarım Politikalart ve Ekonomisi. Edition: 1, Chapter: 13, 283-298, Akçağ Yayınevi,

TÜİK. (2021). Türkiye $\mathrm{Su}$ Ürünleri İstatistikleri. Https://Data.Tuik.Gov.Tr/Kategori/Getkategori? $\mathrm{P}=$ tarim-111\&dil=1 (29/10/2021)

Yıldırım, Ö. \& Okumuş, İ. (2004). Muğla İli’nde su ürünleri yetiştiriciliği ve Türkiye su ürünleri yetiştiriciliğindeki yeri. E.Ü. Su Ürünleri Dergisi. 21(3-4), 361-364. 